\title{
False head complexity and evidence of predator attacks in male and female hairstreak butterflies (Lepidoptera: Theclinae: Eumaeini) from Mexico
}

\author{
Eric Novelo Galicia ${ }^{1}$, Moisés Armando Luis Martínez ${ }^{2}$, Carlos Cordero ${ }^{\text {Corresp. } 3}$ \\ 1 Facultad de Ciencias, Universidad Nacional Autónoma de México, Ciudad de México, Mexico \\ 2 Museo de Zoología "Alfonso L Herrera", Departamento de Biología Evolutiva, Facultad de Ciencias, Universidad Nacional Autónoma de México, Ciudad de \\ México, Mexico \\ 3 Departamento de Ecología Evolutiva, Instituto de Ecología, Universidad Nacional Autónoma de México, Ciudad de México, México \\ Corresponding Author: Carlos Cordero \\ Email address: cordero@ecologia.unam.mx
}

In many butterfly species, the posterior end of the hindwings of individuals perching with their wings closed resembles a butterfly head. This "false head" pattern is considered an adaptation to deflect predator attacks to less vulnerable parts of the body. The presence of symmetrical damage in left and right wings is considered evidence of failed predator attacks to perching butterflies. In this research, we tested the prediction derived from the deflection hypothesis that the degree of resemblance of the false head area (FH) to a real head, as measured by the number of FH "components" (eyespots, "false antennae", modified outline of the $\mathrm{FH}$ area and lines converging on the $\mathrm{FH}$ area) present in the hindwings, is positively correlated to the frequency of symmetrical damage in the $\mathrm{FH}$ area. We studied specimens from two scientific collections of butterflies of the subfamily Theclinae (Lycaenidae) belonging to the Universidad Nacional Autónoma de México (Colección Nacional de Insectos [CNIN] and Museo de Zoología, Facultad de Ciencias [MZFC]). We scored the presence of symmetrical damage in a sample of 20,709 specimens (CNIN: 3,722; MZFC: 16,987) from 126 species (CNIN: 78 species; MZFC: 117 species; 71 species shared by both collections) whose hindwings vary in the number of $\mathrm{FH}$ components, and found that, as predicted, the proportion of specimens with symmetrical damage increases as the number of $\mathrm{FH}$ components increases. We also tested the hypothesis that behavioural differences between the sexes makes males more prone to receive predator attacks and, thus, we predicted a higher frequency of symmetrical damage in the $\mathrm{FH}$ of males than in that of females. We found that the frequency of symmetrical damage was not significantly different between males and females, suggesting that behavioural differences between the sexes produce no differences in the risk of being attacked. Overall, our results provide support to the idea that the FH of 
butterflies is an adaptation that deflects predator attacks to less vulnerable parts of the body in both sexes. 


\section{False head complexity and evidence of predator attacks in}

\section{2 male and female hairstreak butterflies (Lepidoptera:}

\section{Theclinae: Eumaeini) from Mexico}

5 Eric Novelo Galicia ${ }^{1}$, Moisés Armando Luis-Martínez ${ }^{2}$, Carlos Cordero ${ }^{3}$

$7 \quad{ }^{1}$ Facultad de Ciencias, Universidad Nacional Autónoma de México, Ciudad de México, México

$8 \quad$ 2 Museo de Zoología "Alfonso L. Herrera", Departamento de Biología Evolutiva, Facultad de

9 Ciencias, Universidad Nacional Autónoma de México, Ciudad de México, México

$10{ }^{3}$ Departamento de Ecología Evolutiva, Instituto de Ecología, Universidad Nacional Autónoma

11 de México, Ciudad de México, México

Corresponding author:

14 Carlos Cordero

Departamento de Ecología Evolutiva, Instituto de Ecología, Universidad Nacional Autónoma de

México, Circuito exterior s/n, Ciudad Universitaria, Coyoacán 04510, Ciudad de México,

17 México

E-mail address: cordero@ecologia.unam.mx 
20 In many butterfly species, the posterior end of the hindwings of individuals perching with their

21 wings closed resembles a butterfly head. This "false head" pattern is considered an adaptation to

22 deflect predator attacks to less vulnerable parts of the body. The presence of symmetrical

23 damage in left and right wings is considered evidence of failed predator attacks to perching

24 butterflies. In this research, we tested the prediction derived from the deflection hypothesis that

25 the degree of resemblance of the false head area (FH) to a real head, as measured by the number

26 of FH "components" (eyespots, "false antennae", modified outline of the FH area and lines

27 converging on the FH area) present in the hindwings, is positively correlated to the frequency of

28 symmetrical damage in the FH area. We studied specimens from two scientific collections of

29 butterflies of the subfamily Theclinae (Lycaenidae) belonging to the Universidad Nacional

30 Autónoma de México (Colección Nacional de Insectos [CNIN] and Museo de Zoología, Facultad

31 de Ciencias [MZFC]). We scored the presence of symmetrical damage in a sample of 20,709

32 specimens (CNIN: 3,722; MZFC: 16,987) from 126 species (CNIN: 78 species; MZFC: 117

33 species; 71 species shared by both collections) whose hindwings vary in the number of FH

34 components, and found that, as predicted, the proportion of specimens with symmetrical damage

35 increases as the number of FH components increases. We also tested the hypothesis that

36 behavioural differences between the sexes makes males more prone to receive predator attacks

37 and, thus, we predicted a higher frequency of symmetrical damage in the FH of males than in

38 that of females. We found that the frequency of symmetrical damage was not significantly different between males and females, suggesting that behavioural differences between the sexes

40 produce no differences in the risk of being attacked. Overall, our results provide support to the

41 idea that the FH of butterflies is an adaptation that deflects predator attacks to less vulnerable

42 parts of the body in both sexes. 


\section{INTRODUCTION}

44 Predation is a major selective pressure responsible for numerous prey adaptations (Wickler, 1968; Ruxton et al., 2004). In butterflies, visually oriented predators have selected for several components of the colour pattern and morphology of the wings (Robbins, 1980; Howse, 2014; Rossato et al., 2018). The deflection of predator attacks to 'expendable' parts of the body is a type of defence (Cooper, 1998; Humphreys \& Ruxton, 2018) that appears to be present in several butterfly species in which the posterior end of the hindwings resembles a butterfly head (at least to the human eye) when the butterfly perches with its wings closed (Fig. 1; Wickler, 1968; Robbins, 1980; Cordero, 2001; Ruxton et al., 2004). The 'false head' (FH hereafter) is composed of a number of wing pattern and wing shape elements (Robbins, 1980; Cordero, 2001) that vary between species and produce different degrees of similarity to a real head. The four FH components identified by Robbins (1981) (and slightly modified by us) are the following: (1) Presence of colour patterns in the posterior end of the hindwings resembling eyes (= eyespots; Fig. 1: Pseudolycaena damo). (2) Presence of tails resembling antennae in the posterior end of the hindwings (Fig. 1). (3) Outline of the posterior end of the hindwings modified in a way that resembles the contour of a head (Fig. 1: both species, but specially clear in Pseudolycaena damo). (4) Presence, in the ventral side of both wings, of lines converging towards the posterior end of the hindwings (Fig. 1: Arawacus sito; Fig. 2: Micandra cyda and Laothus erybathis); these lines presumably direct the "predator's eye" to the FH area. FHs are particularly frequent in species belonging to the subfamily Theclinae (Lycaenidae) (Robbins, 1980) and behaviours possibly enhancing deception by the FH have been identified (Robbins, 1980; Cordero, 2001). Although there are observations of predators directing their attacks to the butterfly FH (Van Someren, 1922; Sourakov, 2013; López-Palafox \& Cordero, 2017), published reports are 
66

67

68

scant. Further support for the deflection function of FHs comes from a recent study in which salticid spiders were exposed to virtual prey (resembling insects) on a computer screen (Bartos $\&$ Minias, 2016). The spiders preferred to attack the head of the virtual prey, but they were induced to increasingly attack the rear end as the experimenters added FH components (i.e., eyespots, tails resembling antennae, etc.) to the virtual prey. On the other hand, indirect evidence supporting the deflection hypothesis comes from two studies documenting symmetrical damage in the FH area, a likely result of failed predator attacks (Robbins, 1981; Tonner et al., 1993).

Direct observations confirm symmetrical damage in the FH area of both hindwings resulting from predator attacks (Van Someren [1922] observations of lizard attacks; López-Palafox \& Cordero, personal observations of mantid attacks).

Robbins (1981) reasoned that if the number of FH components in the wings of a butterfly species influences its degree of deceptiveness for predators, then that number should be directly proportional to the fraction of individuals exhibiting symmetrical damage in the FH area. This author analyzed rates of symmetrical damage in the FH area of Neotropical species of the tribe Eumaeini (Lycaenidae: Theclinae) that vary in the number of FH components. He used two samples, one of "more than 1,000 specimens of about 125 species" collected over a period of 5 weeks in an area of $0.5 \mathrm{~km}^{2}$ in Colombia, and another of "almost 400 specimens of about 75 species" collected over a period of three months in Panama, and found support for his hypothesis. Here, we first provide further tests of Robbins' hypothesis by analyzing two samples of Lycaenidae with characteristics different from those used by him. We used specimens belonging to two scientific collections, which were captured by different collectors in several localities covering many parts of Mexico, along a period of several decades. Secondly, since in many Lycaenidae species males employ a sit-and-wait mate location strategy, perching in 
89

90

91

92

93

94

95

96

97

consecutive days in the same places, at the same time of the day and returning to the same perches after inspecting flying objects (Johnson \& Borgo, 1976; Alcock, 1983; Cordero \& Soberón, 1990; Fischer \& Fiedler, 2001; Takeuchi \& Imafuku, 2005a, b; Salazar, 2011; Dinesh $\&$ Venkatesh, 2013), we also explored the hypothesis that males, due to their stationary, conspicuous and predictable behaviour, suffer higher rates of predator attacks than females.

\section{MATERIALS AND METHODS}

\section{Scoring evidence of predator attacks and number of false head components in collection} specimens

We studied pinned specimens from two scientific collections of Mexican Theclinae (Lycaenidae) belonging to the Universidad Nacional Autónoma de México. The first sample is part of the Colección Nacional de Insectos of the Instituto de Biología (hereafter CNIN), and the second sample is part of the collection of butterflies of the Museo de Zoología "Alfonso L. Herrera" of the Facultad de Ciencias (hereafter MZFC).

To assess the hypothesis that the fraction of individuals exhibiting symmetrical damage in the FH area is directly proportional to the number of FH components, we examined a total of 20,709 specimens (CNIN: 3,722; MZFC: 16,987) of 126 species (CNIN: 78 species; MZFC: 117 species; 71 of these species were present in both collections) belonging to 52 genera (species names according to Robbins, 2004). We only included in our study species with at least 10 specimens. We recorded the presence of symmetrical damage (i.e., very similar in both hindwings) in the FH area (Fig. 2). We did not considered symmetrical damage: (a) the loss of all or most of both hindwings, (b) damage in the FH area that had a different shape in each hindwing (Fig. 2), and (c) damage in the FH area resulting from aging (i.e. ragged wings). We 
111 scored, for each species, the number of FH components described in the first paragraph of the

112 introduction (Fig. 1), briefly: (1) eyespots, (2) tails ("false antennae"), (3) modified outline of the

113 posterior end of the hindwings, and (4) presence of lines converging in the FH area in the ventral

114 side of the wings. The number of FH components was used as an estimate of FH similarity to a

115 real head or FH "complexity". To test the hypothesis that the proportion of specimens exhibiting

116 symmetrical damage in the FH area is larger in males than in females, we used the sample of

117 species in which the sex of the specimens was recorded in the labels (all 78 species from the

118 CNIN; Appendix 1) or was determined by us (75 of the 117 species from the MZFC; Appendix $1191)$.

\section{Statistical analyses}

121 We used generalized linear mixed models (GLMMs) with Poisson error distribution and log link

122 function to evaluate the effect of number of FH components on the probability of specimens

123 having symmetrical damage. Since a phylogeny including all species in our sample is not

124 available, we first performed analyses considering each species as an independent data point. We support this decision on Robbins' (1981) evidence that FH components evolve rapidly. However,

126 in an attempt to consider a possible role of phylogenetic inertia (Blomberg \& Garland, 2002), we

127 also ran the analyses at the genus level (using average numbers of FH components and of

128 specimens with symmetrical damage). In a second set of models using the subset of species (or 129 genera) for which sex was determined, the effect of sex and the interaction of sex and number of 130 FH components were also included.

132 symmetrical damage; the logarithm of the total specimens was included as an offset to convert 133 this to a proportion (Hilbe, 2011). The fixed effect of main interest was the number of FH 
134 components, and the collection of origin (MSFC or CNIN) was included as a fixed effect in all

135 models to account for differences in the overall level of damage between collections (e.g. due to

136 differences in collection locations, seasons, collectors). In the two models in which sex and the

137 interaction between sex and number of FH components were considered, they were included as

138 fixed effects. Finally, since proportions of specimens with symmetrical damage were calculated

139 separately by collection in the first set of models and by sex and collection in the second set,

140 there were multiple measures of most species or genera. Species was therefore included as a

141 random intercept effect in species level models and genus as a random intercept in genus level

142 models to account for these multiple measures.

We simplified initial models via backwards-stepwise simplification, in which the effects

144 of variables on the model were tested by removing the variables in order from least- to most

145 significant P-value, comparing these nested models using ANOVA, and removing variables

146 whose removal does not provoke a significant effect, until only significant variables remain

147 (resulting in the "minimum adequate model"; Crawley, 2013). We also evaluated the models

148 using the Akaike Information Criterion (AIC) with similar results (shown in Appendix 2). We

149 generated all statistical analyses and graphs in the R statistical software, version $3.5 .1(R$

150 Development Core Team, 2016) using the RStudio interface, version 1.1.456 (RStudio Team,

151 2015). GLMMs were constructed using the "Ime4" package, version 1.1-20 (Bates et al., 2014).

152 Graphs were generated using the package "sciplot" (Murdoch, 2017). Model diagnostics

153 (homogeneity of variance and normality of residuals, and lack of over/underdispersion, outliers,

154 and zero-inflation) were verified by inspection of simulated residuals using the "DHARMa"

155 package (Hartig, 2019) and were fulfilled by all models. We include the R code used in these

156 models in Appendix 3. 


\section{RESULTS}

\section{General observations}

159 In the whole sample, the percentage of specimens with symmetrical damage in the FH area was

$1601.21 \%(\mathrm{~N}=251=\mathrm{CNIN}: 32+$ MZFC: 219). In the sub-sample of specimens whose sex was

161 recorded, the proportion of specimens with symmetrical damage in the FH area was similar to

162 that in the whole sample, $1.31 \%(\mathrm{~N}=173=\mathrm{CNIN}: 32+\mathrm{MZFC}: 141)$. The mean percentage of

163 individuals with symmetrical damage per species was small in both collections: $1.02 \%$ (median $=$ $1640 \%, \mathrm{Q}_{25 \%}-\mathrm{Q}_{75 \%}=0-0.7 \%$, minimum-maximum $\left.=0-10 \%\right)$ in the CNIN and $1.38 \%$ (median $=$

$1650.150 .12 \%, \mathrm{Q}_{25 \%}-\mathrm{Q}_{75 \%}=0-0 \%$, minimum-maximum $\left.=0-15.4 \%\right)$ in the MZFC. The

166 percentage of species with at least one specimen with symmetrical damage was almost twice as

167 large in the MZFC collection (59 species, $50.4 \%$ of the sample) than in the CNIN collection (21

168 species, $26.3 \%$ of the sample $)($ Chi-squared $=10.69, \mathrm{P}=0.0011, \mathrm{df}=1)$.

169

170

171

172

173

174

175

176

177 178

\section{Effect of number of FH components on evidence of attacks in the FH area}

As expected, in both the analyses at the species and at the genus level, we found highly significant positive effects of the number of FH components on the proportions of specimens with symmetrical damage in the FH area (Table 1, Figs. 3A and 3B). Analyses at both levels also detected an effect of the collection of origin of the data on the proportions of specimens with symmetrical damage (Table 1): these proportions were significantly larger in collection MZFC than in collection CNIN (Figs. 3A and 3B).

\section{Effect of sex of the specimens on evidence of attacks in the FH area}

The data did not support the prediction that the percentage of individuals with symmetrical damage in the FH area would be larger in males than in females. Neither in the analyses at the 
179 species level nor at the genus level, the sex of the specimens or the interaction between sex and

180 number of FH components had a significant effect on the proportion of specimens with

181 symmetrical damage (Table 2). As in the previous section, in the sample of species in which the

182 sex of the specimens was known, at both the species and genus level, a significant and positive

183 effect of the number of FH components on the proportion of specimens with symmetrical

184 damage was found (Table 2). However, in contrast to the previous section, the effect of the

185 collection of origin of the data on the proportion of specimens with symmetrical damage was

186 significant only in the genus level analysis, where a larger proportion of specimens with

187 symmetrical damage was also detected in the MZFC collection (Table 2).

\section{DISCUSSION}

The shapes and colours that make butterfly wings aesthetically appealing to humans are, in large part, products of the evolutionary pressures imposed by predators (Howse, 2014; Rossato et al., 2018). The "false head" of Lycaenidae is considered an adaptation for deflecting predator attacks to less vulnerable areas of the animal. Robbins (1980) found that the complexity of FHs is positively associated with the proportion of specimens with symmetrical damage in the $\mathrm{FH}$ area, a likely evidence of failed predator attacks (Van Someren, 1922; López-Palafox \& Cordero, personal observations). Here, using larger and more heterogeneous samples, we confirm that the probability of finding symmetrical damage in the FH area is larger in species and genera with more FH components (Tables 1 and 2, Fig. 3), providing further evidence for the role of predator deflection in the evolution of butterfly false heads and for the idea that FHs with more components are better at deceiving predators.

In contrast, our hypothesis that the sit-and-wait mate location strategy employed by males of many Lycaenidae species (Johnson \& Borgo, 1976; Alcock, 1983; Cordero \& Soberón, 1990; 
202 Fischer \& Fiedler, 2001; Takeuchi \& Imafuku, 2005a, b; Salazar, 2011; Dinesh \& Venkatesh,

203 2013) results in males being more stationary and behaviourally conspicuous than females, and

204 thus more prone to be attacked by visually oriented predators, was not supported by the data.

205 Males and females did not differ in the proportion of specimens with symmetrical damage (Table

206 2). It is possible that our generalization is wrong and the number of species in which males

207 exhibit sit-and-wait mate location behaviour is much smaller than we think. If this is the case, the

208 prediction that males will suffer higher rates of attack should be tested only in species exhibiting

209 sit-and-wait male mate location strategy. Furthermore, female behaviour, especially egg laying

210 and nectar feeding, could expose females to a predation risk similar to that experienced by males.

211 In fact, the lack of obvious sexual differences in FH traits observed in our samples also point

212 against our hypothesis.

213 If we accept the conclusion that a FH with all four components is better at deflecting

214 predator attacks, then we need to understand why species with different numbers of FH

215 components frequently coexist in the same location (e.g. Robbins, 1981; López-Palafox et al.,

216 2015). Robbins (1981) considered that genetic restrictions or ecological factors could be

217 responsible for explaining variation in FH complexity. Robbins (1981) considers unlikely that

218 genetic restrictions provide a general explanation, because evidence indicates that $\mathrm{FH}$

219 components evolve rapidly. Our data are consistent with this point of view: 11 of the 26 genera

220 (42\%) with more than one species in our database have species belonging to two ( 8 genera) or

221 three (3 genera) different categories of number of FH components (Table 3). Thus, ecological

222 factors could provide better explanations for the diversity observed in FH patterns. Species with

223 different numbers of $\mathrm{FH}$ components could represent alternative adaptive solutions to selective

224 pressures from visually oriented predators when we consider additional traits. For example, a 
225 species with a "complete" FH could be rather conspicuous when perched (Fig. 1), whereas a

226 species like Callophrys xami with only eyespots and tails (López-Palafox \& Cordero, 2017), but

227 with the ventral side of the wings of green colour, could be hard to spot when posed on or near

228 leaves, as well as being able to deflect predator attacks to the $\mathrm{FH}$ once it is detected. The

229 morphological components of the FH considered in this paper are complemented with

230 behaviours that possibly enhance the deceptive effect (Robbins, 1980; Cordero, 2001; see also

231 Hoskins \& Bálint, 2016), such as the back-and-forth movement of the hindwings along the

232 sagittal plane frequently performed while resting by Theclinae species (López-Palafox \&

233 Cordero, 2017) and a few species of other groups (Riodinidae, Robbins, 1985; Nymphalidae,

234 Sourakov, 2015). The interaction of these behavioural traits with the morphological components

235 could also help explain the interspecific variation in the complexity of the FH.

236

One of the referees of this paper (Dr. A. Krupitsky) noted the interesting fact that in some

237 species the degree of development or even the number of some of the FH components varies

238 between individuals (the reviewer mentions Cyanophrys spp., Micandra cyda and Oenomaus

239 ortygnus among these species). We did not consider this possibility in our study and, thus, we

240 did not look for intraspecific variation in the FH components. In our opinion, quantitative

241 documentation of the extent of this variation and its distribution between the different taxa, as

242 well as its possible relationships with the average number of FH components and sex (among

243 other variables), is an important subject for future research. Speculate about the possible causes

244 of such intraspecific variation seems premature, although relaxed selection from reduced

245 predation pressure comes to mind as one possible hypothesis. Additionally, species with

246 substantial intraspecific variation could be used as "natural treatments" in the functional study of 
247 FH components, in experiments similar to that of López Palafox \& Cordero (2017) on "false 248 antennae".

\section{CONCLUSIONS}

250 The false head $(\mathrm{FH})$ hindwing pattern is considered an adaptation to deflect predator attacks 251 away from the real head, to less vulnerable parts of the body. We tested one prediction of this

252 hypothesis using two large samples of museum specimens. Since FHs vary between species in 253 the number of morphological and colour components ("complexity"), we predicted a positive 254 correlation between the number of FH components and the proportion of specimens with 255 evidence of predator attacks directed to the $\mathrm{FH}$ area. We found the predicted association whether 256 we used species or genus as a sample unit. We also tested the related hypothesis that behavioural 257 differences between the sexes makes males more prone than females to receive predator attacks. 258 Contrary to our prediction, we found that the proportion of specimens with evidence of predator 259 attacks directed to the FH area was not different between males and females. Overall, our results 260 support the deflection hypothesis and the idea that FHs with more elements are better at 261 deceiving predators, and suggest that behavioural differences between the sexes produce no 262 differences in the risk of being attacked.

\section{ACKNOWLEDGEMENTS}

264 We thank Drs. Jorge Llorente and Alejandro Zaldívar for allowing us to study the specimens 265 from the collections of the Museo de Zoología "Alfonso L. Herrera" (Facultad de Ciencias, 266 UNAM) and the Colección Nacional de Insectos (Instituto de Biología, UNAM), respectively.

267 We thank Dr. Lynna Kiere for her critical help with the statistical analyses. We thank Juan

268 Carlos García Morales for allowing us to use his excellent photographs in Figure 1. We thank the 
269 thoughtful commentaries of Drs. Zsolt Bálint, Anatoly Krupitsky and Andrei Sourakov on a

270 previous version of the manuscript. We thank Isabel Vargas, María Cristina Mayorga and Raúl

271 Iván Martínez for superb technical support.

\section{REFERENCES}

273

274

275

276

277

278

279

280

281

282

283

284

285

286

287

288

Alcock J. 1983. Territoriality by hilltopping males of the great purple hairstreak, Atlides halesus (Lepidoptera: Lycaenidae): convergent evolution with a pompilid wasp. Behavioral Ecology and Sociobiology 13:57-62 DOI 10.1007/BF00295076.

Bartos M, Minias P. 2016. Visual cues used in directing predatory strikes by the jumping spider Yllenus arenarius (Araneae, Salticidae). Animal Behaviour 120:51-59 DOI 10.1016/j.anbehav.2016.07.021.

\section{Bates D, Maechler M, Bolker B, Walker S, Bojesen Christensen RH, Singmann H. 2014.} lme4: Linear mixed-effects models using Eigen and S4. Retrieved from https://github.com/lme4/lme4/ http://lme4.r-forge.r-project.org.

Blomberg SP, Garland Jr T. 2002. Tempo and mode in evolution: phylogenetic inertia, adaptation and comparative methods. Journal of Evolutionary Biology 15:899-910 DOI 10.1046/j.1420-9101.2002.00472.x.

Cooper Jr. WE. 1998. Conditions favoring anticipatory and reactive displays deflecting predatory attack. Behavioral Ecology 9:598-604 DOI 10.1093/beheco/9.6.598.

Cordero C. 2001. A different look at the 'false head' of butterflies. Ecological Entomology 26:106-108 DOI 10.1046/j.1365-2311.2001.00287.x. 
289 Cordero C, Soberon J. 1990. Non-resource based territoriality in males of the butterfly Xamia 290 xami (Lepidoptera: Lycaenidae). Journal of Insect Behavior 3:719-732 DOI 10.1007/BF01065961.

292

293 294

295

296

297

298

299

300

301

302

303

304

305

306

307

308

Crawley MJ. 2013. The R Book Second Edition. Sussex (UK): Wiley.

Dinesh AS, Venkatesha MG. 2013. Analysis of the territorial, courtship and coupling behavior of the hemipterophagus butterfly, Spalgis epius (Westwood) (Lepidoptera: Lycaenidae). Journal of Insect Behavior 26:149-164 DOI 10.1007/s10905-012-9341-9.

Fischer K, Fiedler K. 2001. Resource-based territoriality in the butterfly Lycaena hippothoe and environmentally induced behavioural shifts. Animal Behaviour 61:723-732 DOI 10.1006/anbe.2000.1662.

Hartig F. 2019. DHARMa: Residual Diagnostics for Hierarchical (Multi-Level/Mixed) Regression Models. R package. Retrieved from http:/florianhartig.github.io/DHARMa/

Hilbe JM. 2011. Negative Binomial Regression. Cambridge (UK): Cambridge University Press.

Hoskins A, Bálint Z. 2016. Arcas - A case of spider mimicry? (Lepidoptera: Lycaenidae: Theclinae: Eumaeini). Lepidoptera Novae 9:33-36.

Howse P. 2014. Seeing butterflies. New perspectives on colour, patterns \& mimicry. UK: Papadakis Publisher, 176.

Humphreys RK, Ruxton GD. 2018. What is known and what is not yet known about deflection of the point of a predators attack. Biological Journal of the Linnean Society 123:483-495 DOI 10.1093/biolinnean/blx164/4830222. 
309 Johnson K, Borgo PM. 1976. Patterned perching behavior in two Callophrys (Mitoura)

310 (Lycaenidae). Journal of the Lepidopterists' Society 30:69-183.

311

312

313

314

315

316

317

López-Palafox TG, Luis-Martínez A, Cordero C. 2015. The movement of "false antennae" in butterflies with "false head" wing patterns. Current Zoology 61:758-764 DOI 10.1093/czoolo/61.4.758.

López-Palafox TG, Cordero C. 2017. Two-headed butterfly vs. mantis: Do false antennae matter? PeerJ 5:e3493 DOI 10.7717/peerj.3493.

Murdoch, M. M. with code developed by the R. D. C. T. with general advice from the R. listserv community and especially D. 2017. sciplot: Scientific Graphing Functions for Factorial Designs. R package. Retrieved from https://cran.rproject.org/package=sciplot.

R Development Core Team. 2016. R: A language and environment for statistical computing. Vienna: R Foundation for Statistical Computing. Retrieved from https:/www.r-project.org.

Robbins R. 1980. The Lycaenid "false head" hypothesis: Historical review and quantitative analysis. Journal of the Lepidopterists' Society 34:194-208.

Robbins R. 1981. The "False head" hypothesis: Predation and wing pattern variation in Lycaenid butterflies. American Naturalist 118:770-775 DOI 10.1086/283868.

Robbins R. 1985. Independent evolution of "false head" behavior in Riodinidae. Journal of the Lepidopterists' Society 39:224-225 .

Robbins R. 2004. “Lycaenidae. Theclinae. Tribe Eumaeini.” In Checklist: Part 4A. Hesperioidea-Papilionoidea, ed. G. Lamas, pp. 118-137. Atlas of Neotropical Lepidoptera, Volume 5A, ed. J. B. Heppner. Gainesville, Fla.: Scientific Publishers. 
330

331

332

333

334

335

336

337

338

339

340

341

342

343

344

345

346

347

348

349

350

351

Rossato DO, Kaminski LA, Iserhard CA, Duarte L. 2018. More than colours: An ecoevolutionary framework for wing shape diversity in butterflies. Advances in Insect Physiology 54:55-84 DOI 10.1016/bs.aiip.2017.11.003.

RStudio Team. 2015. RStudio: Integrated Development for R. Boston, MA: RStudio, Inc.

Ruxton GD, Sherratt TN, Speed MP. 2004. Avoiding attack: The evolutionary ecology of crypsis, warning signals, and mimicry. Oxford (UK): Oxford University Press, 252.

Salazar JA. 2011. Nota sobre los hábitos territoriales de Laothus gibberosa Hewitson, Adelotypa densemaculata Hewitson y Pseudotinea vulcanicus Callahan y Salazar en residuos de bosques fragmentados (Lepidoptera: Lycaenidae, Riodinidae). Boletin Cientifico del Museo de Historia Natural de Caldas 15:206-216.

Sourakov A. 2013. Two heads are better than one: false head allows Calycopis cecrops (Lycaenidae) to escape predation by a jumping spider, Phidippus pulcherrimus (Salticidae). Journal of Natural History 47:1047-1054 DOI 10.1080/00222933.2012.759288.

Sourakov A. 2015. Antipredation and "antimimicry": wing pattern is supported by behavior in Archaeoprepona chromus (Lepidoptera: Nymphalidae: Preponini). ATL Notes, December.

Takeuchi T, Imafuku M. 2005a. Territorial behavior of Favonius taxila (Lycaenidae): territory size and persistency. Journal of Research on the Lepidoptera 38:59-66.

Takeuchi T, Imafuku M. 2005b. Territorial behavior of a green hairstreak Chrysozephyrus smaragdinus (Lepidoptera: Lycaenidae): site tenacity and wars of attrition. Zoological Science 22:989-994 DOI 10.2108/zsj.22.989. 
352 Tonner M, Novotný V, Lepš J, Komárek S. 1993. False head wing pattern of the Burmese 353 junglequeen butterfly and the deception of avian predators. Biotropica 25:474-478.

354 Van Someren VGL. 1922. Notes on certain color patterns in Lycaenidae. Journal of the East $355 \quad$ Africa and Uganda Natural History Society 17:18-21.

356 Wickler W. 1968. El mimetismo en las plantas y los animales. Madrid: McGraw-Hill: Biblioteca 357 para el Hombre Actual No. 29, 256.

358 Wourms W, Wasserman FE. 1985. Butterfly wing markings are more advantageous during handling than during the initial strike of an avian predator. Evolution 39:845-851 DOI $10.2307 / 2408684$. 
Figure 1

Two examples of "false heads" as seen in perching Lycaenidae butterflies

(A) Pseudolycaena damo. (B) Arawacus sito. False head components indicated with arrows.

Photo credit: Juan Carlos García Morales. 


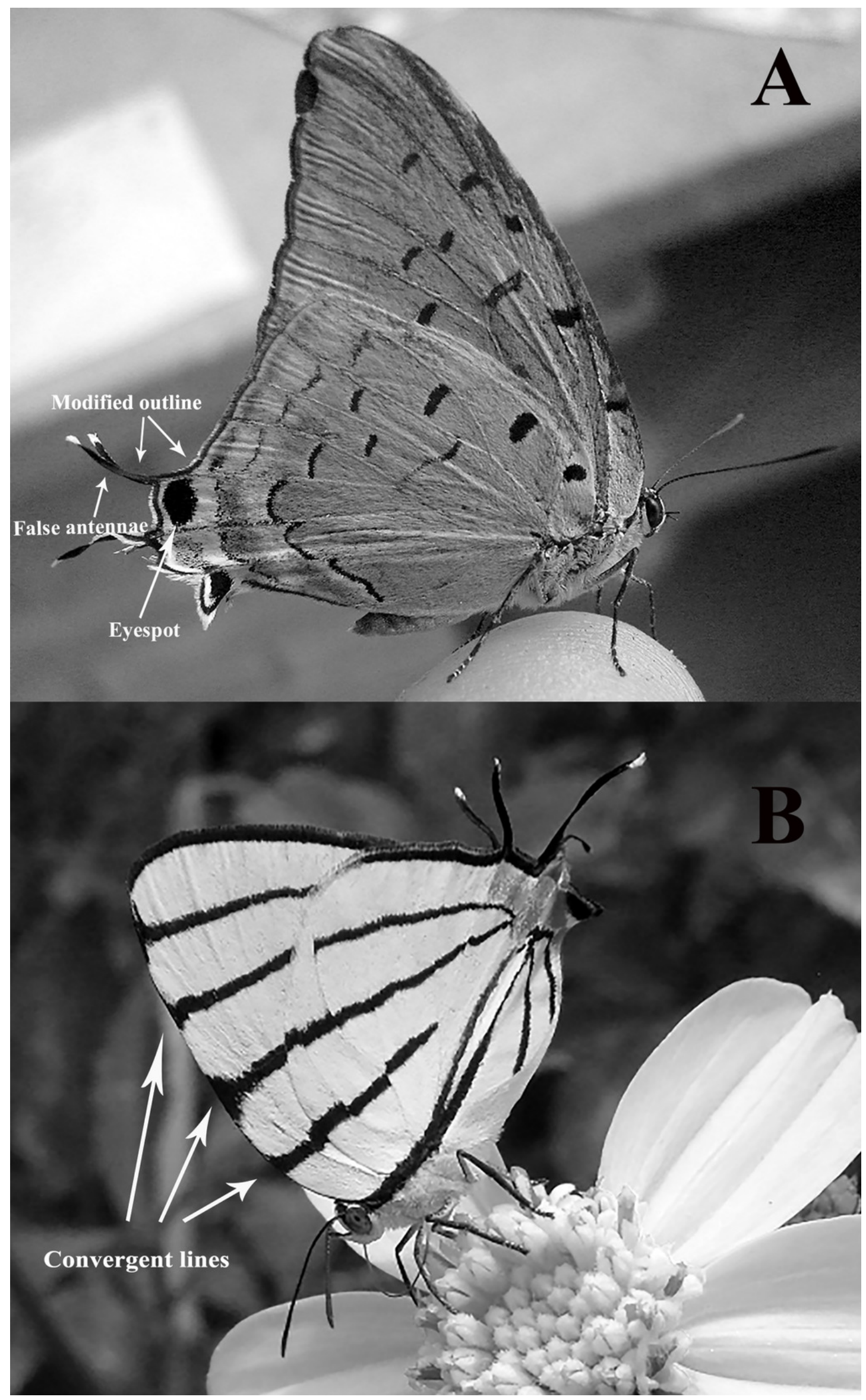

Peer) reviewing PDF | (2019:03:36009:1:1:NEW 14 May 2019) 


\section{Figure 2}

Examples of the ventral wing surfaces of pinned specimens of "false head" butterfly species (Lepidoptera: Lycaenidae: Theclinae).

(A-C) Micandra cyda (Q). (D-F) Pseudolycaena damo (o'). (G-I) Laothus erybathis (\$). (A) (D) (G) specimens with almost intact hindwings. (B) (E) (H) specimens with symmetrical damage in the false head area (considered evidence of deflected predator attacks). (C) (F) (I) specimens with non-symmetrical damage in the false head area. Photo credit: Raúl Iván Martínez. 

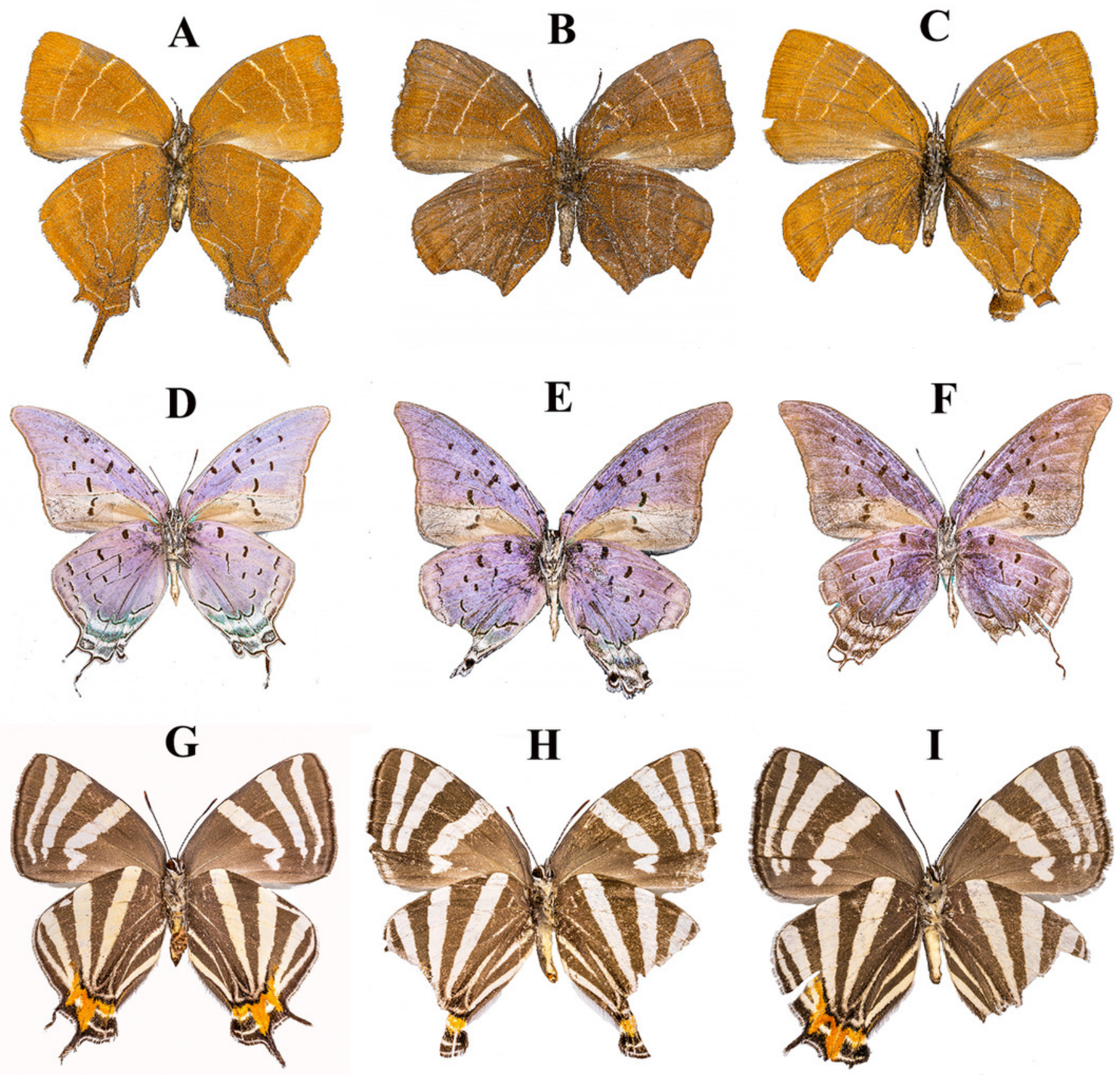


\section{Figure 3}

Effect of the number of false head components on the proportion of individuals per species (A) and per genus (B) with symmetrical damage.

Proportions were calculated separately for each of the two scientific collections where specimens were examined. Each point represents the average per species (A) or genus (B) within each collection (closed points: CNIN, open points: MZFC); error bars show standard error. Curves show the predicted proportion of individuals with damage based on negative binomial generalized linear models, accounting for the significant additive effect of collection (solid line: CNIN, dashed line: MZFC). At the genus level (b), the average of the number of FH components per genus was used. 
A

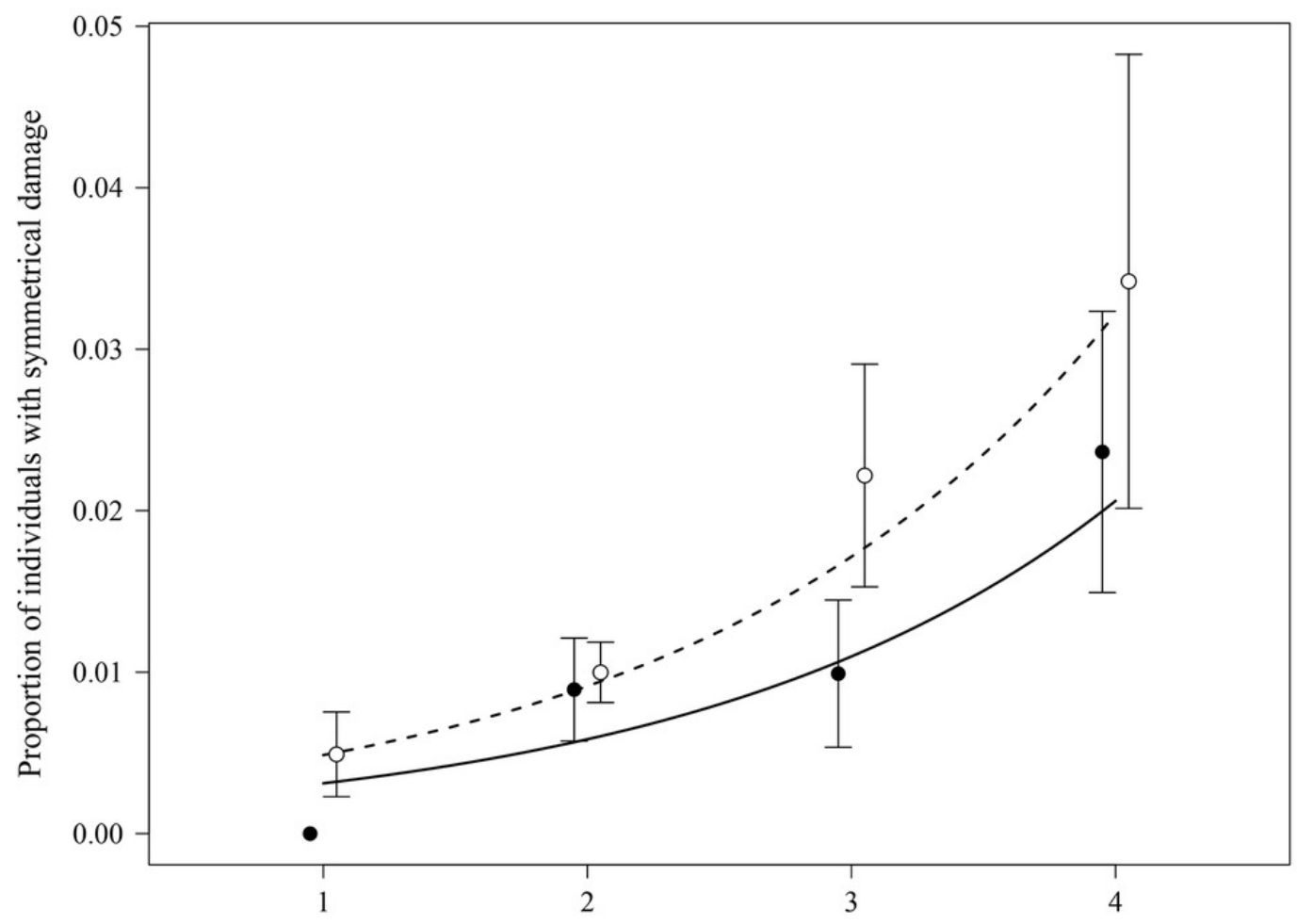

False Head Components

B

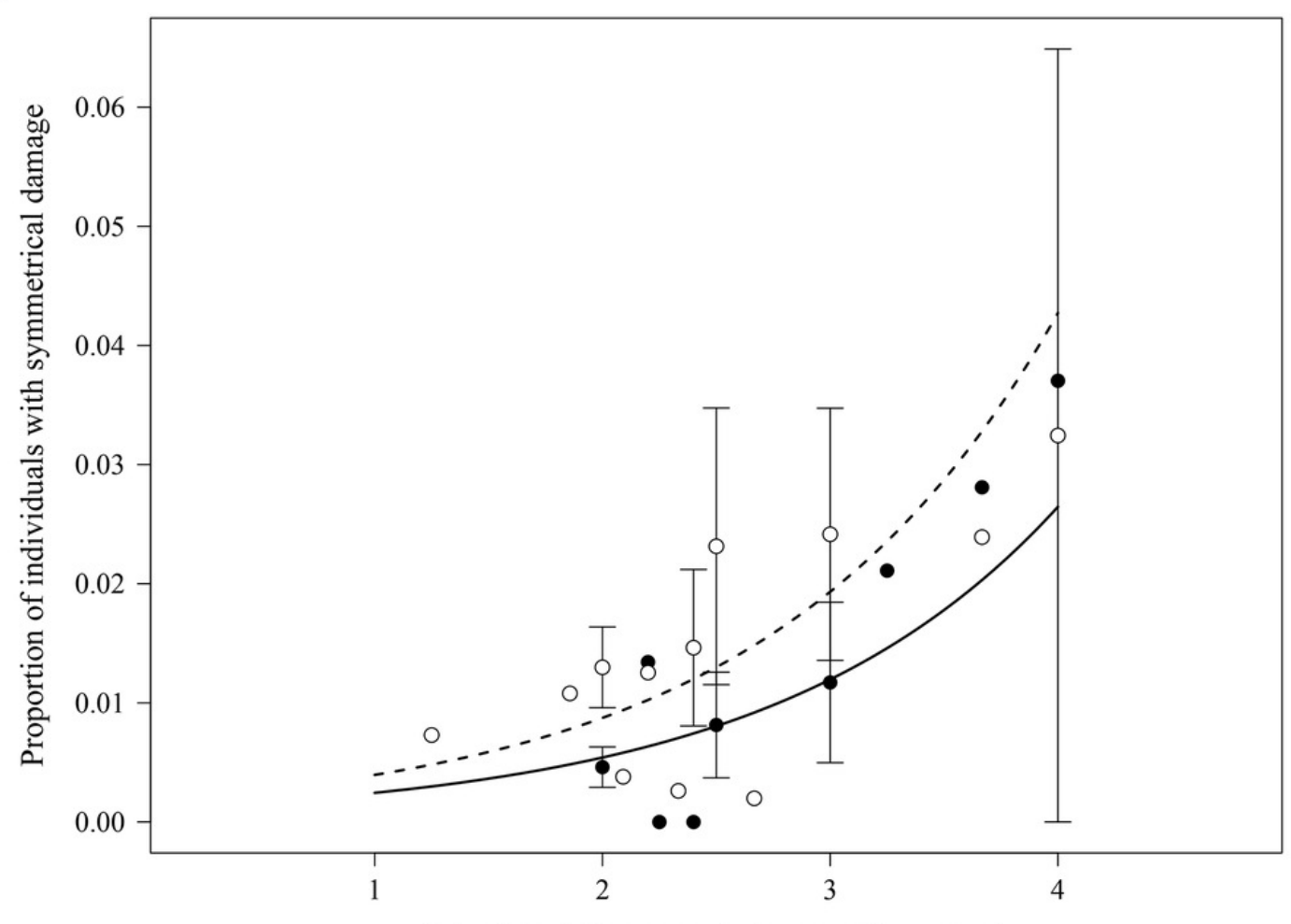

False Head Components (averaged by genus) 


\section{Table $\mathbf{1}$ (on next page)}

Results of models evaluating the effects of the number of false head (FH) components and the collection of origin (MZFC or CNIN) on the probability of symmetrical damage at the species (a) and genus (b) level.

In both cases, both the number of $\mathrm{FH}$ components and collection of origin had significant effects, such that the initial model is the minimum adequate model. Significant $P$-values are in bold type. 
2

\begin{tabular}{lllll}
\hline Fixed Effects & $\beta \pm \mathrm{SE}^{*}$ & $\mathrm{Z}^{*}$ & $\mathrm{P}_{\mathrm{Z}}{ }^{*}$ & $P_{\chi 2^{\S}}$ \\
\hline
\end{tabular}

a) Species level
Number of FH components
$0.6291 \pm 0.1701$
3.757
$1.72 \times 10^{-4}$
$3.103 \times 10^{-4}$
Collection (MZFC-CNIN)
$0.4000 \pm 0.1952$
2.049
0.0405
0.0325
Random effects: $\quad \sigma_{\text {species }}^{2}=0.6987 \quad n=197$ total observations from 124 species

b) Genus level

\begin{tabular}{lccccc} 
Number of FH components & 0.7465 & \pm 0.2329 & 3.205 & $\mathbf{1 . 3 5} \times \mathbf{1 0}^{-3}$ & $\mathbf{4 . 0 0 6} \times \mathbf{1 0}^{-3}$ \\
Collection (MZFC-CNIN) & 0.5168 & \pm 0.1937 & 2.668 & $\mathbf{7 . 6 4} \times \mathbf{1 0}^{-3}$ & $\mathbf{6 . 9 5} \times \mathbf{1 0}^{-3}$ \\
Random effects: $\quad \sigma_{\text {genus }}^{2}=0.4494$ & & $n=81$ total observations from 49 genera \\
\hline
\end{tabular}

${ }^{*}$ Parameters from model

$\S P$-value resulting from $\chi^{2}$ nested model comparisons following removal of each variable during backwards stepwise simplification 


\section{Table 2 (on next page)}

Results of models evaluating the effects of sex and the interaction of sex and number of false head $(\mathrm{FH})$ components, in addition to number of $\mathrm{FH}$ components and collection of origin (MZFC or CNIN), on the probability of symmetrical damage at the species (a

In both models, sex and the interaction between sex and number of $\mathrm{FH}$ components were non-significant and therefore were removed from the initial models $(a, c)$, leaving number of $\mathrm{FH}$ components and collection of origin as the only variables in the minimum adequate models (b, d). Significant $P$-values are in bold type. 
Fixed Effects

$\beta \pm \mathrm{SE}^{*}$

$Z^{*}$

$\mathrm{P}_{\mathrm{Z}}^{*}$

$P_{\chi 2^{\S}}$

a) Species level initial (complete) model

Number of FH components

$0.7459 \pm 0.2299$

3.244

1.874

$1.18 \times 10^{-3}$

$7.652 \times 10^{-3}$

Collection (MZFC-CNIN)

$0.3989 \pm 0.2129$

1.783

0.06095

0.055

Sex

$1.1220 \pm 0.6293$

$-1.795$

0.07459

0.8001

Number of FH components * Sex

$-0.3851 \pm 0.2145$

0.07259

0.0724

Random effects: $\quad \sigma_{\text {species }}^{2}=0.5674 \quad n=306$ total observations from 105 species

b) Species level minimum adequate model

$\begin{array}{lccccc}\text { Number of FH components } & 0.4999 & \pm 0.1827 & 2.736 & \mathbf{6 . 2 1} \times \mathbf{1 0}^{-3} & --- \\ \text { Collection (MZFC-CNIN) } & 0.3955 & \pm 0.2126 & 1.860 & 0.06282 & ---\end{array}$

Random effects: $\quad \sigma_{\text {species }}^{2}=0.5478 \quad n=306$ total observations from 105 species

c) Genus level initial (complete) model

$\begin{array}{lrrrrr}\text { Number of FH components } & 0.6274 & \pm 0.2840 & 2.209 & \mathbf{0 . 0 2 7 2} & \mathbf{0 . 0 4 8 8} \\ \text { Collection (MZFC-CNIN) } & 0.3999 & \pm 0.2035 & 1.966 & \mathbf{0 . 0 4 9 3} & \mathbf{0 . 0 4 2 4} \\ \text { Sex } & 0.6065 & \pm 0.6769 & 0.896 & 0.3703 & 0.8300 \\ \text { Number of FH components * Sex } & -0.2165 & \pm 0.2479 & -0.873 & 0.3825 & 0.3842\end{array}$

Random effects: $\quad \sigma^{2}$ genus $=0.4399 \quad n=150$ total observations from 47 genera

d) Genus level minimum adequate model

$\begin{array}{llllll}\text { Number of FH components } & 0.4936 & 0.2415 & 2.044 & \mathbf{0 . 0 4 1} & -- \\ \text { Collection (MZFC-CNIN) } & 0.3989 & 0.2035 & 1.960 & \mathbf{0 . 0 5 0} & \text {--- }\end{array}$

Random effects: $\quad \sigma_{\text {genus }}^{2}=0.4404 \quad n=150$ total observations from 47 genera

*Parameters from model

$\S P$-value resulting from $\chi^{2}$ nested model comparisons following removal of each variable during backwards stepwise simplification 


\section{Table 3(on next page)}

Genera in which species with different numbers of false head (FH) components were observed.

Subscript numbers in parenthesis indicate the number of species with that number of $\mathrm{FH}$ components in our sample (see Appendix 1 for species names) 


\begin{tabular}{lc}
\hline Genus & $\begin{array}{c}\text { Number of FH components in } \\
\text { different species }\end{array}$ \\
\hline 1. Arawacus & $3_{(1)}, 4_{(2)}$ \\
2. Atlides & $2_{(4)}, 3_{(1)}$ \\
3. Contrafacia & $2_{(1)}, 3_{(1)}$ \\
4. Cyanophrys & $1_{(1)}, 2_{(6)}$ \\
5. Erora & $1_{(2)}, 2_{(2)}$ \\
6. Rekoa & $2_{(3)}, 3_{(2)}$ \\
7. Theritas & $2_{(2)}, 3_{(2)}$ \\
8. Tmolus & $2_{(1)}, 3_{(2)}$ \\
\hline 9. Ministrymon & $1_{(1)}, 2_{(2)}, 3_{(3)}$ \\
10. Panthiades & $2_{(1)}, 3_{(1)}, 4_{(2)}$ \\
11. Strymon & $1_{(2)}, 2_{(6)}, 3_{(3)}$ \\
\hline \hline
\end{tabular}

1 